tôi. Tác giả Miller và cs trong quá trình theo dõi các mắt có lỗ hoàng điểm chấn thương cho nhận định rằng các mắt có thị lực cuối cùng tốt hơn là những mắt có vùng ellipsoid được bảo toàn nhiều hơn. ${ }^{4}$ Chúng tôi cũng quan sát thấy những trường hợp lỗ hoàng điểm đóng type 2 sau phẫu thuật thường đi kèm với vùng ellipsoid trước và sau phấu thuật khá lớn $(3043,25$ um so với $2617 \mu \mathrm{m}$ ). Điêu này cũng gợi ý cho chúng tôi tiên lượng về thị lực sau mổ khá kém của nhóm bệnh nhân nghiên cứu.

Chúng tôi cũng đánh giá kích thước đỉnh và đáy lố hoàng điểm trước và sau điều trị trong các trường hợp lỗ hoàng điểm đóng type 2 . Kết quả cho thây kích thước đỉnh lỗ hoàng điểm có xu hướng giảm tuy nhiên sự khác biệt không có ý nghĩa thống kê. Tuy nhiên kích thước đáy lỗ hoàng điểm trước và sau điêu trị giảm có ý nghĩa thống kê với $p<0.05$. Như vậy với những trường hợp đóng lỗ hoàng điểm type 2 sau phẩu thuật, chúng tôi thấy lỗ hoàng điểm trên OCT có thu hẹp về kích thước.

\section{KẾT LUẬN}

Lỗ hoàng điểm chấn thương là môt bênh cảnh nặng ảnh hưởng nghiêm trọng đến chức năng thị giác. Tỉ lệ đóng lỗ hoàng điểm chấn thương của nhóm nghiên cứu nói chung sau một đến hai phẫu thuật và tỉ lê thành công đóng iỗ hoàng điểm sau một lần phẫu thuật còn khá hạn chế. Gần một nửa nhóm nghiên cứu có thị lực cải thiện trên 2 dòng sau phẫu thuật 3 tháng. Chiều dày trung tâm hoàng điểm sau phẫu thuật có xu hướng giảm so với trước phẫu thuật. Vùng ellipsoid giảm nhẹ khi so sánh trước và sau phẫu thuật, không có ý nghĩa thống kê. Trung tâm hoàng điểm teo mỏng và vùng ellipsoid rộng sau phẫu thuật hướng đến một tiên lượng không tốt về hồi phục thị lực của nhóm bệnh nhân. So sánh giữa trước và sau phẫu thuật, kích thước đỉnh lố hoàng điểm có xu hướng giảm với sự khác biệt không có ý nghĩa thống kê, kích thước đáy lỗ hoàng điểm giảm có ý nghĩa thống kê.

\section{TÀI LIẸU THAM KHẢO}

1. Kelly NE, Wendel RT. Vitreous surgery for idiopathic macular holes: results of a pilot study. Archives of ophthalmology. 1991;109(5):654-659.

2. Amari F, Ogino $N$, Matsumura $M$, Negi A, Yoshimura N. Vitreous surgery for traumatic macular holes. Retina (Philadelphia, Pa). 1999;19(5):410-413.

3. Kang S, Ahn K, Ham D. Types of macular hole closure and their clinical implications. British Journal of Ophthalmology. 2003;87(8):1015-1019.

4. Miller JB, Yonekawa $Y$, Eliott $D$, et al. Longterm follow-up and outcomes in traumatic macular holes. American Journal of Ophthalmology. 2015;160(6):1255-1258. e1.

5. Yuan L, Han J, Xiaorong L. Clinical analysis of 47 cases with traumatic macular hole resulted from ocular contusion. Chinese Journal of Ocular Fundus Diseases. 2015;31(1):45-48.

6. Ghoraba HH, Ellakwa AF, Ghali AA. Long term result of silicone oil versus gas tamponade in the treatment of traumatic macular holes. Clinical ophthalmology (Auckland, NZ). 2012;6:49.

7. Miller JB, Yonekawa Y, Eliott D, Vavvas DG. A review of traumatic macular hole: diagnosis and treatment. International Ophthalmology Clinics. 2013;53(4):59-67.

8. Chen $\mathbf{H}-\mathbf{J}$, Jin $\mathbf{Y}$, Shen $\mathbf{L - J}$, et al. Traumatic macular hole study: a multicenter comparative study between immediate vitrectomy and sixmonth observation for spontaneous closure. Annals of translational medicine. 2019;7(23)

\title{
PHÂN TÍCH CÁC YẾU TỐ LIÊN QUAN ĐẾN SÃN SÀNG CHI TRẢ CHO NộI SOI ĐẠI TRỰC TRÀNG ĐỂ SÀNG LỌC UNG THƯ ĐẠI TRỰC TRÀNG TẠI VIỆT NAM
}

\section{TÓM TẮT}

Mục tiêu: Phân tích các yếu tố liên quan đến sẵn sàng chi trả (WTP) đối với xét nội soi đại trực tràng để sàng lọc ung thư đại trực tràng tại Việt Nam. Phương

*Trường Đại học Y tế Công cộng

Chịu trách nhiệm chính: Nguyễn Quỳnh Anh

Email: nqa@huph.edu.vn

Ngày nhận bài: 4.3.2021

Ngày phản biên khoa học: 28.4.2021

Ngày duyệt bài: 11.5.2021

\section{Nguyễn Quỳnh Anh*, Nguyễn Thu Hà*}

pháp: Sử dụng bộ số liệu trên 402 đối tượng 50-75 tuổi đến khám bệnh thông thường tại các phòng khám ngoại trú thuộc Trung tâm y tế quận Hoàn Kiếm từ tháng 1 đến tháng 3/2019. Phân tích mối liên quan bằng mô hình hồi quy đa biến phân tích mối liên quan giữa WTP với các biến số độc lâp (nhân khẩu - xã hô̂i học, yếu tố nguy cơ của ung thư đại trực tràng và kiến thức-thái độ về ung thư đại trực tràng). Kết quả và kết luận: Lựa chọn sẵn sàng chi trả đối với nội soi đại trực tràng được chỉ ra là có liên quan có ý nghĩa thống kê với thu nhập, tình trạng đang làm việc hiện tại, số thành viên trong hộ gia đình, người thẩn trực hệ trong gia đình có ít nhất một yếu tố nguy cơ với 
ung thư đại trực tràng (như bệnh dạ dày, trĩ, bệnh tim mạch, trâm cảm, ung thư khác) và mức chi trả được đưa ra. Ước tính trung bình và trung vị WTP sau khi hiệu chỉnh với các yếu tố liên quan là 718.390 đồng (95\%KTC: 653.980; 800.780) và 587.670 đồng (95\%KTC: 537.500; 640.080).

Tư khóa: Sẵn sàng chi trả, đo lường sự ưa thích lý thuyết, phương pháp lượng giá ngẩu nhiên phụ thuộc, yếu tố liên quan

\section{SUMMARY}

\section{ANALYSIS OF FACTORS ASSOCIATED WITH WILLINGNESS TO PAY FOR COLORECTAL CANCER SCREENING USING COLONOSCOPY IN VIETNAM}

Objective: To analyze the driving factors of willingness to pay (WTP) for colonoscopy for colorectal cancer screening in Vietnam.Method: Employing logistic regression to analyze associated factors of WTP. We used the data from a crosssectional survey employing contigent valuation method with double-bounded question design to estimate willingness to pay for FOBT. Survey was conducted on 402 patients aged 50-75 years old who went to the outpatient clinics of Hoan Kiem District Medical Center from January to March 2019. Results and conclusion: The choice of WTP for colonscopy was shown to be significantly related to variables including income, current working status, number of household members, his relatives have at least one risks for developing colorectal cancer. When adjusting the value of WTP for those related factors, the mean and median WTP are 718,390 VND (95\%CI: 653,980 ; $800,780)$ and 587,670 VND (95\%CI: 537,500; $640,080)$, respectively.

Keywords: Willingness to pay, stated preference, contigent valuation, WTP, CV, driving factors, colonoscopy.

\section{I. ĐẶT VẤN ĐỀ}

Nội soi đại trực tràng (10 năm một lần) là một trong những xét nghiệm sàng lọc phổ biến nhất, bênh canh tìm máu ẩn trong phân (FOBT), nội soi đại tràng sigma ống mềm (FS), xét nghiệm hóa miễn dịch phân (FIT), được đề cập đến trong các hướng dẫn sàng lọc ung thư đại trực tràng trên toàn thế giới [1]. Việc ước tính sẵn sàng chi trả (WTP, willingness-to-pay) của người dân đối với sàng lọc ung thư đại trực tràng sử dụng nội soi đại trực tràng được đánh giá là rất quan trọng nhằm cung cấp các thông tin để xác định mức đồng chi trả phù hợp khi người dân sử dụng dịch vụ để vừa có thể đảm bảo nguồn tài chính cho các cơ sở cung ứng dịch vụ nhưng đồng thời cũng đảm bảo ở mức đồng chi trả như vậy, tỷ lệ tiếp cận và sử dụng dịch vụ sàng lọc là tối ưu [2].

Một trong các nghiên cứu đầu tiên tại Việt Nam được công bố năm 2020 của tác giả Nguyễn Thu Hà và Nguyễn Quỳnh Anh về Đánh giá mức sẵn sàng chi trả đối với một số can thiệp phát hiện sớm ung thư tại Việt Nam [3]. Nghiên cứu được thực hiện từ tháng 1 đến tháng 3/2019, áp dụng phương pháp lượng giá ngẫu nhiên phụ thuộc (Contigent Valuation) để xác định mức WTP đối với các xét nghiệm sàng lọc ung thư đại trực tràng (sử dụng FOBT và nội soi đại trực tràng). Nghiên cứu tiến hành thu thập số liệu sử dụng các câu hỏi Có-Không hai mức trên 402 đối tượng là người dân đến khám bệnh thông thường có độ tuổi từ 50-75 tuổi tại các phòng khám bệnh ngoại trú của Trung tâm y tế Quận Hoàn Kiểm. Trong bài báo này, chúng tôi tập trung đi sâu phân tích các yếu tố ảnh hưởng đến lựa chọn sẵn sàng chi trả (choice of WTP) của đối tượng đối với sàng lọc ung thư đại trực tràng sử dụng nội soi đại trực tràng. Việc xác định các yếu tố tiển lượng lựa chọn và mức WTP có ý nghĩa quan trọng trong việc xây dựng các kế hoạch sàng lọc trong tương lai, cũng như xác định các mức đồng chi trả cho sàng lọc ung thư đại trực tràng sử dụng nội soi đại trực tràng trong tương lai để đảm bảo tỷ lệ sử dụng dịch vụ là tối ưu. Bên cạnh đó, bài báo này cũng gợi mở một số yếu tố rào cản của sàng lọc ung thư đại trực tràng sử dụng nội soi đại trực tràng. Các can thiệp giúp giảm bớt các rào cản này được đánh giá có ý nghĩa then chốt đối với các chương trình sàng lọc ung thư đại trực tràng trong tương lai.

\section{II. ĐỐl TƯỢNG VÀ PHƯƠNG PHÁP NGHIÊN CỨU}

Tiến hành phân tích dựa trên các biến số đặc thù liên quan đến WTP của sàng lọc ung thư đại trực tràng sử dụng nội soi đại trực tràng trong bộ số liệu đo lường WTP của tác giả Nguyễn Thu Hà và Nguyễn Quỳnh Anh (2020)[3]. Phương pháp nghiên cứu của nghiên cứu này như sau:

2.1. Thiết kế nghiên cứu cắt ngang, sử dụng phương pháp lượng giá ngẫu nhiên phụ thuộc (Contingent Valuation) để xác định mức WTP đối với các xét nghiệm sàng lọc ung thư đại trực tràng (thông qua thực hiện xét nghiệm máu ẩn trong phân (FOBT) và nội soi đại trực tràng).

2.2. Đối tượng nghiên cứu: Người dân đến khám bệnh tại cơ sở y tế ban đầu trên địa bàn thành phố Hà Nội thỏa mãn các tiêu chuẩn lựa chọn sau: (i) từ 50 đến 75 tuổi; (ii) Chưa từng tham gia sàng lọc ung thư đại trực tràng; (iii) đồng ý tham gia phỏng vấn và đủ khả năng nghe nói hiểu tiếng Việt, không mắc bệnh tâm thần.

3.3. Thời gian thu thập số liệu: Từ tháng 1 đến tháng 3 năm 2019. 
3.4. Địa điểm thu thập số liệu: Các phòng khám thuộc Trung tâm y tế quận Hoàn Kiếm - là cơ sở chăm sóc sức khỏe ban đầu.

3.5. Cỡ mẫu và phương pháp chọn mẫu: Áp dụng phương pháp ước tính cõ̃ mẫu của Robert C. Mitchell và Richard T Carson [4], thực tế thu thập được số liệu của 402 đối tượng.

3.6. Biến số nghiên cứu: bao gồm các nhóm biến số chính (i) Thông tin cá nhân bao gồm thông tin nhân khẩu-xã hội học, kiến thức và thái độ đối với sàng lọc ung thư đại trực tràng, yếu tố nguy cơ của ung thư đại trực tràng; (ii) Thông tin mô tả bối cảnh đưa ra quyêt định về mức WTP; (iii) Nhóm câu hỏi nhằm xác định mức độ WTP sử dụng câu hỏi Có - Không hai mức; (iv) Nhóm câu hỏi nhằm khẳng định lý do đối tượng trả lời theo các lựa chọn đã đưa ra.
3.7. Nhập liệu, quản lý số liệu: Tiến hành nhập vào phần mềm Epi Data 3.1, sau đó làm sạch và được xử lý bằng phần mềm $R$.

3.8. Phân tích số liệu: Sử dụng gói phân tích $\mathrm{DCchoice}$ của phần mềm $\mathrm{R}$ dành riêng cho nghiên cứu lượng giá ngẫu nhiên phụ thuộc sử dụng thiết kế câu hỏi có/không nhiều mức để phân tích số liệu. Mô hình đa biến sử dụng phương pháp ước tính mức sẵn sàng chi trả tuyến tính (parametric approach) với phân bố giả định của mức sẵn sàng chi trả là log-logistic.

\section{KẾT QUẢ NGHIÊN CứU}

3.1. Thông tin chung về đối tượng. Bảng 1 trình bày thông tin về đặc điểm nhân khẩu - xã hội học, thái độ đối với ung thư đại trực tràng của đối tượng tham gia nghiên cứu.

Bảng 1: Một số đặc điểm của đôî tượng nghiên cứu

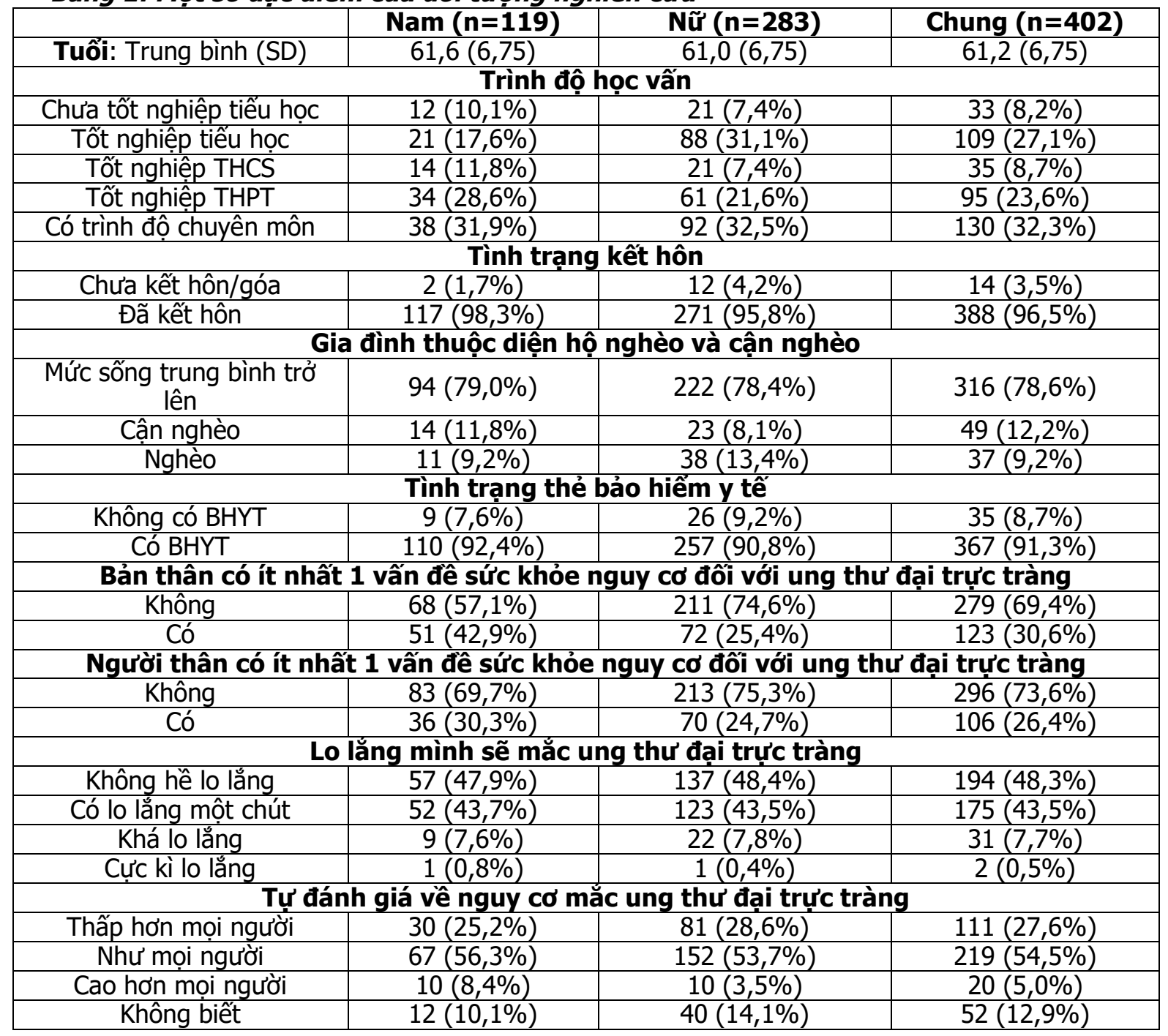




\begin{tabular}{|c|c|c|c|}
\hline \multicolumn{5}{|c|}{ Lý do lớn nhất khiến người dân không thực hiện sàng lọc sử dụng nội soi đại trực tràng } \\
\hline Thiếu kiến thức & $9(7,6 \%)$ & $23(8,1 \%)$ & $32(8,0 \%)$ \\
\hline Sợ hãi & $41(34,5 \%)$ & $99(35,0 \%)$ & $140(34,8 \%)$ \\
\hline Rào cản về thời gian & $5(4,2 \%)$ & $4(1,4 \%)$ & $9(2,2 \%)$ \\
\hline Rào cản về chi phí & $45(37,8 \%)$ & $87(30,7 \%)$ & $132(32,8 \%)$ \\
\hline Khác & $1(0,8 \%)$ & $2(0,7 \%)$ & $3(0,7 \%)$ \\
\hline Không trả lời & $18(15,1 \%)$ & $68(24,0 \%)$ & $86(21,4 \%)$ \\
\hline
\end{tabular}

3.2. Yếu tố liên quan đến lựa chọn chi trực hệ trong gia đình có ít nhất một yếu tố nguy trả cho nội soi đại trực tràng. Bảng 2 trình cơ với ung thư đại trực tràng (như bệnh da dày, bày kết quả phân tích của mô hình đa biến. trĩ, bệnh tim mạch, trầm cảm, ung thư khác) và Trong đó, lựa chọn sẵn sàng chi trả (choice of mức chi trả được đưa ra. Dấu của giá trị hệ số WTP) với nội soi đại trực tràng được chỉ ra là có cho thấy chiều của mối liên quan nhưng không liên quan có ý nghĩa thống kê với các biến số chỉ ra được mức độ của mối liên quan. Dấu của bao gồm thu nhập, tình trạng đang làm việc hiện giá trị hệ số cho thấy chiều của mối liên quan tại, số thành viên trong hộ gia đình, người thẩn nhưng khồng chỉ ra được mức độ của mối liên quan.

Bảng 2: Môi liên quan giữa sẵn sàng chi trả cho nội soi đại trực tràng và các biến số độc lập

\begin{tabular}{|c|c|c|c|c|c|}
\hline Các biến số & Hệ số & SD & $\mathbf{Z}$ & \multicolumn{2}{|c|}{$\mathbf{P}$} \\
\hline Hằng số & 16,290 & 1,883 & 8,655 & 0,000 & $* * *$ \\
\hline Tuối & $-0,006$ & 0,019 & $-0,310$ & 0,757 & \\
\hline Thu nhập & 0,001 & 0,000 & 9,043 & 0,000 & $* * *$ \\
\hline Giới & $-0,188$ & 0,253 & $-0,743$ & 0,458 & \\
\hline Đã kết hôn & $-0,740$ & 0,609 & $-1,214$ & 0,225 & \\
\hline Hiện tại đang làm việc & $-0,922$ & 0,299 & $-3,081$ & 0,002 & ** \\
\hline Trình độ học vấn & 0,008 & 0,081 & 0,097 & 0,923 & \\
\hline Số thành viên trong hộ gia đình & 0,331 & 0,068 & 4,859 & 0,000 & $* * *$ \\
\hline Số con & $-0,121$ & 0,118 & $-1,024$ & 0,306 & \\
\hline Là người kiếm tiền chính trong gia đình & 0,162 & 0,274 & 0,592 & 0,554 & \\
\hline Lo lắng mình sẽ mắc ung thư đại trực tràng & 0,380 & 0,258 & 1,476 & 0,140 & \\
\hline $\begin{array}{l}\text { Đánh giá bản thân có nguy cơ mắc ung thư đại trực } \\
\text { tràng bằng hoặc cao hơn }\end{array}$ & $-0,256$ & 0,292 & $-0,875$ & 0,382 & \\
\hline $\begin{array}{c}\text { Người thân có ít nhất } 1 \text { yếu tố nguy cơ ung thư đại } \\
\text { trực tràng }\end{array}$ & $-0,748$ & 0,268 & $-2,794$ & 0,005 & ** \\
\hline Có ít nhất 1 yếu tố nguy cơ ung thư đại trực tràng & 0,057 & 0,265 & 0,213 & 0,831 & \\
\hline Đã từng sàng lọc ung thư đại trực tràng & 0,113 & 0,213 & 0,532 & 0,594 & \\
\hline Ua thích nội soi ung thư đại trực tràng & 0,413 & 0,244 & 1,696 & 0,090 & . \\
\hline Có bảo hiếm y tế & 0,290 & 0,374 & 0,774 & 0,439 & \\
\hline Đi khám bệnh cùng người nhà & $-0,154$ & 0,244 & $-0,629$ & 0,530 & \\
\hline Mức chi trả (a) & $-2,921$ & 0,161 & $-18,161$ & 0,000 & **** \\
\hline
\end{tabular}

Ghi chú: Mô hình đa biến, sử dụng phương pháp tuyến tính với phân bố log-logistic. Phân tích sử dụng gói phân tích "DCchoice" trên nền tảng phần mềm $\mathrm{R}$.

$\mathrm{N}=372 ; \quad A I C=910 ; B I C=985 ; L L=-436$; (a) biến đổi hàm logarit; $* * *$ mức ý nghĩa thống kê $0.001 ; * *$ mức ý nghĩa thống kê 0.01 ; * mức ý nghĩa thống kê 0.05

Bảng 3 giúp đưa ra một số ước tính về giá trị sẵn sàng chi trả đối với xét nghiệm tìm máu ẩn trong phân FOBT khi đối tượng có các đặc điểm khác nhau. Trong đó, sau khi hiệu chỉnh với các yếu tố liên quan, ước tính giá trị trung bình WTP nói chung là 718.390 đồng (95\%KTC: 653.980 ; 800.780). Giá trị trung vị WTP là 587.670 đồng (95\%KTC: 537.500; 640.080).

Bảng 3: Ước tính mức sẵn sàng chi trả đôi với FOBT sau khi hiệu chỉnh dựa trên các yếu tố liên quan

\begin{tabular}{|c|c|c|}
\hline & Trung bình WTP (95\%CI) & Trung vị WTP (95\%CI) \\
\hline Chung & $718.390(653.980 ; 800.780)$ & $587.670(537.500 ; 640.080)$ \\
\hline Nữ: Hiện đang làm việc & & 470.920 \\
\hline Có lo lắng mình sẽ mắc ung thư & 575.670 & 4 \\
\hline
\end{tabular}


VIETNAM MEDICAL JOURNAL N²2 - MAY - 2021

\begin{tabular}{|c|c|c|}
\hline đại trực tràng & $(446.690 ; 723.200)$ & $(364.720 ; 591.250)$ \\
\hline $\begin{array}{l}\text { Không hề lo lăng mình mắc ung } \\
\text { thư đại trực tràng }\end{array}$ & $\begin{array}{c}505.420 \\
(380.390 ; 683.190)\end{array}$ & $\begin{array}{c}413.450 \\
(308.120 ; 557.470)\end{array}$ \\
\hline \multicolumn{3}{|l|}{ Hiện đang khồng làm việc } \\
\hline $\begin{array}{c}\text { Có lo lắng mình sẽ mắc ung thư } \\
\text { đaai trực tràng }\end{array}$ & $\begin{array}{c}789.220 \\
(661.420 ; 962.550)\end{array}$ & $\begin{array}{c}645.620 \\
(539.710 ; 774.550)\end{array}$ \\
\hline $\begin{array}{l}\text { Không hề lo lắng mình mắc ung } \\
\text { thư đại trực tràng }\end{array}$ & $\begin{array}{c}692.910 \\
(556.810 ; 871.020)\end{array}$ & $\begin{array}{c}566.830 \\
(457.330 ; 703.720) \\
\end{array}$ \\
\hline \multicolumn{3}{|l|}{ Nam: Hiện đang làm việc } \\
\hline $\begin{array}{l}\text { Có lo lắng mình sẽ mắc ung thư } \\
\text { đại trực tràng }\end{array}$ & $\begin{array}{c}613.930 \\
(456.240 ; 818.870)\end{array}$ & $\begin{array}{c}502.220 \\
(372.980 ; 669.800)\end{array}$ \\
\hline $\begin{array}{l}\text { Không hề lo lắng mình mắc ung } \\
\text { thư đại trực tràng }\end{array}$ & $\begin{array}{c}539.010 \\
(401.100 ; 749.610)\end{array}$ & $\begin{array}{c}440.930 \\
(327.870 ; 607.640)\end{array}$ \\
\hline \multicolumn{3}{|l|}{ Hiện đang khống làm việc } \\
\hline $\begin{array}{c}\text { Có lo lắng mình sẽ mắc ung thư } \\
\text { đại trực tràng }\end{array}$ & $\begin{array}{c}841.670 \\
(661.420 ; 1.089 .330)\end{array}$ & $\begin{array}{c}688.520 \\
(539.940 ; 877.160)\end{array}$ \\
\hline $\begin{array}{l}\text { Không hề lo lắng mình mắc ung } \\
\text { thư đại trực tràng }\end{array}$ & $\begin{array}{c}738.960 \\
(577.360 ; 973.110)\end{array}$ & $\begin{array}{c}604.500 \\
(470.330 ; 778.110)\end{array}$ \\
\hline
\end{tabular}

\section{BÀN LUÂN}

Lựa chọn sẵn sàng chi trả (choice of WTP) cho nội soi đại trực tràng được chỉ ra là có liên quan có ý nghĩa thống kê với các biến số bao gồm thu nhập, tình trạng đang làm việc hiện tại, số thành viên trong hộ gia đình, người thân trực hệ trong gia đình gặp phải ít nhất 1 vấn đề sức khỏe nguy cơ đối với ung thư đại trực tràng (như bệnh dạ dày, trĩ, bệnh tim mạch, trầm cảm, ung thư khác) và mức chi trả được đưa ra. Kết quả được chỉ ra từ nghiên cứu này vừa có những điểm tương đồng và điểm khác biệt với một số nghiên cứu trên thế giới, chẳng hạn như một nghiên cứu về sẵn sàng chi trả đối với sàng lọc ung thư đại trực tràng, phổi và tụy của tác giả Sandra và cộng sự công bố năm 2016 tại Anh kết hợp thẻ chi trả kểt hợp với phương pháp đặt câu hỏi có/không (3 mức) dựa trên phần mềm máy tính. Trong nghiên cứu này, tuổi và thời gian đến cơ sở y tế không được chỉ ra là có liên quan đến giá WTP, ngược lại các yếu tố bao gồm thu nhập, trình độ học vấn và trước đó đã tham gia chẩn đoán ung thư đại trực tràng là các yếu tố ảnh hưởng đến giá trị WTP [2]. Hoặc trong tổng quan tài liệu công bổ năm 2011 với 11 nghiên cứu ước tính WTP đối với các sàng lọc ung thư đại trực tràng cũng tóm tắt các yếu tố ảnh hưởng đến giá WTP bao gồm các yếu tố về dân số và kinh tế-xã hội của đối tượng như tuổi, giới, tôn giáo, thu nhập và trình độ học vấn; các yếu tố liên quan đến tình trạng bệnh, nhận thức về nguy cơ và tình trạng bệnh trong gia đình; và độ nhạy, độ đặc hiệu của các kỹ thuật chẩn đoán [5].

Việc sử dụng các biến số liên quan được chỉ ra từ nghiên cứu này có thể đóng vai trò quan trọng trong việc xây dựng các mô hình tiên lượng mức sẵn sàng chi trả của đối tượng. Tuy nhiên việc lựa chọn các biến số sử dụng trong mô hình tiên lượng cần phải được thực hiện một cách thận trọng nhằm đảm bảo tính chính xác cũng như tính thực tiễn của mô hình tiên lượng. Kết hợp với các cơ sở dữ liệu sẵn có, chẳng hạn như các thông tin đã được thu thập trong trang thông tin chung của toàn bộ đối tượng người dân tại Hà Nội đã tham gia sàng lọc trong chương trình sàng lọc ung thư đại trực tràng miễn phí đã diễn ra tại Hà Nôii năm 2018 (bao gồm các thông tin cơ bản như tuổi, giới tính, biểu hiện về tiêu hóa và yếu tố nguy cơ liên quan đến gia đình), việc xác định mức giá xét nghiệm FOBT và nội soi đại trực tràng để tối ưu hóa tỷ lệ người dân tham gia sàng lọc là hoàn toàn có thể thực hiện được.

Nhóm nghiên cứu cũng xem xét chi tiết các rào cản được đối tượng chỉ ra trong việc thực hiện nội soi đại trực tràng. Rào cản phổ biến nhất được chỉ ra liên quan đến sự "sợ hãi khi phát hiện ra bệnh", "sợ đến bệnh viện", "sợ gây mê", "sợ đưa dụng cụ vào cơ thể gẩy khó chịu" hay "sợ đau" (34,8\%). Các rào cản về chi phí trong trường hợp này cũng được chỉ ra với tỷ lê cao hơn so sánh với FOBT với các lý giải phổ biến như "chi phí cao, tốn kém" hay "phải trả thêm phí gây mê đắt tiền". Một số nghiên cứu trên thế giới đã thực hiện về rào cản đối với người dân trong việc thực hiện xét nghiệm FOBT và nội soi đại trực tràng trong các chương trình sàng lọc ung thư đại trực tràng nói chung cũng chỉ ra một số yếu tố tương tự (chẳng hạn sợ hãi, quá trình chuẩn bị khiến đối tượng cảm thây khó chịu, thiếu kiến thức, đau đớn và rào cản liên quan đến chi phí, các vấn đề khác đang hiện 
diện quan trọng hơn, thiếu khuyến cáo từ bác sỹ, không ưu tiên được thời gian để làm xét nghiệm [6]. Việc xem xét chi tiết các rào cản này cũng sẽ đóng vai trò quan trọng trong việc thiết kế được chương trình sàng lọc hiệu quả.

\section{KẾT LUẬN}

Lựa chọn sẵn sàng chi trả (choice of WTP) đối với sàng lọc ung thư đại trực tràng sử dụng nội soi đại trực tràng được chỉ ra là có liên quan có ý nghĩa thống kê với các biến số bao gồm thu nhập, tình trạng đang làm việc hiện tại, số thành viên trong hộ gia đình, người thân trực hệ trong gia đình có ít nhất một yếu tố nguy cơ với ung thư đại trực tràng (như bệnh dạ dày, trĩ, bệnh tim mạch, trầm cảm, ung thư khác) và mức chi trả được đưa ra.

\section{TÀI LIỆU THAM KHẢO}

1. Navarro, M., et al., Colorectal cancer population screening programs worldwide in 2016: An update. World joumal of gastroenterology, 2017. 23(20): p. 3632.

2. Hollinghurst, $S_{\text {., }}$ et al., Using willingness-to-pay to establish patient preferences for cancer testing in primary care. BMC medical informatics and decision making, 2016. 16(1): p. 1-13.

3. Nguyến Thu Hà and Nguyễn Quỳnh Anh, Báo cáo đề tài cấp cơ sở: Đánh giá mức sắn sàng chi trả đối với một số can thiêp phát hiện sớm ung thư tai Việt Nam - Nghiên cứu trường hợp đối với Ung thư đại trực tràng. 2020, Trường Đại học Y tế Công cộng: Hà Nổi, Việt Nam.

4. Mitchell, R.C., R.T. Carson, and R.T. Carson, Using surveys to value public goods: the contingent valuation method. 1989: Resources for the Future.

5. Lin, P.-J., et al., Willingness to pay for diagnostic technologies: a review of the contingent valuation literature. Value In Health, 2013. 16(5): p. 797-805.

6. Jones, R.M., et al., Patient-reported barriers to colorectal cancer screening: a mixed-methods analysis. American journal of preventive medicine, 2010. 38(5): p. 508-516.

\section{NGHIÊN CỨU GIÁ TRI CỦA CHỤP CẮT LỚP VI TÍNH 128 ĐỊNH LƯỢNG TRÊN BỆNH NHÂN BÊ̂NH PHỔI TẮC NGHẼN MẠN TÍNH TRƯớC VÀ SAU GHÉP TẾ BÀO GỐC TỰ THÂN}

\section{TÓM TẮT}

Đại cương. Cắt lớp vi tính định lượng (Quantitative Computed Tomography: QCT) đã được ứng dụng từ nhiều năm nay trên thế giới để đánh giá và định lượng các tổn thương nhu mô phổi trong bệnh lý bệnh phổi tắc nghẽn mạn tính (COPD), bao gồm đinh lượng thể tích khí phế thũng (LAA-950), đánh giá bẫy khí (LAA-856), đo diện tích khu vực thành phế quản (WA), tỷ lệ phân trăm khu vực thành (\%WA), diện tích lòng phế quản (LA), độ dày thành phế quản (WT), các nghiên cứu cho thấy QCT có độ chính xác cao, tương quan chặt chẽ với xét nghiệm đo chức năng hô hấp (FEV1, FVC), phân loại mức độ nặng theo GOLD. Chúng tôi ứng dụng phương pháp nàyy để đánh giá các chỉ số khí phế thũng (LAA-950), bẫy khí (LAA-856),

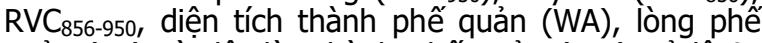
quản (LA) và độ dày thành phế quản (WT), tỷ lệ \% mạch máu của phổi \%HAV của bệnh nhân COPD trước và sau ghép tế bào gốc tự thân từ mô mõ và tuỷ xương. Phương pháp: Nghiên cứu được thực hiên tữ tháng 10.2019 - 10.2020 trên 32 bệnh nhân COPD được chẩn đoán xác định COPD theo tiêu chuẩn GOLD

\footnotetext{
${ }^{1}$ Trung tâm Điện quang, Bệnh viện Bạch Mai 2Trung tâm Hồ hâp-Bệnh viện Bạch Mai, ĐHY Hà Nội Chịu trách nhiệm chính: Trần Anh Tuấn Email: Bs.trananhtuan@yahoo.com.vn Ngày nhận bài: 4.3.2021

Ngày phản biên khoa học: 23.4.2021

Ngày duyệt bài: 12.5.2021
}

\section{Trần Anh Tuấn ${ }^{1}$ Vũ Thành Trung ${ }^{2}$}

2018, những bệnh nhân có FEV1 < 60\% được chọn vào nghiên cứu ghép tế bào gốc tự thân tại Trung tâm hô hấp - Bệnh viện Bạch Mai (4 bệnh nhân GOLD II, 17 bệnh nhân GOLD III, 11 bệnh nhân GOLD IV). Bênh nhân được chup cắt lớp vi tính đinh lương QCT 2 lần, lần 1 trước ghép và lần 2 sau ghép 6 tháng bằng máy chụ CLVT 128 dãy của hãng Siemens (Somatom Definition Egde) tại Trung tâm Điện Quang - Bệnh viên Bach Mai. Kết quả: Tỷ lệ \% khí phế thũng (LAA. 950) trước ghép $31,49 \% \pm 8.19$, sau ghép $32,8 \%$ $\pm 7.13)$, tỷ lề \% bẫy khí ở thì thở ra $\left(\mathrm{LAA}_{-856}\right)$ trước ghép $63,65 \% \pm 8,74$, sau ghép $61,41 \% \pm 7,4$ (khác biệt có ý nghĩa thống kế $\mathrm{p}=0,026), \mathrm{RVC}_{856-950}$ trước ghép $0,83 \pm 1,82$, sau ghép $3,58 \pm 1,76$ (khác biệt có ý nghĩa $\mathrm{p}=0,000$ ), các chí số này tương quan tuyến tính với FEV1, BODE và phân loại GOLD. Tỳ lệ \%WA sau ghép có thay đổi ở nhánh phế quản phẩn thuỳ 1 (trước ghép $70,74 \%$, sau ghép $67,59 \%, p=0,02$ ) và nhánh hạ phân thuỳ 1 (trước ghép $79,19 \%$, sau ghép $75,90 \%, p=0,01$ ), diện tích (LA), đường kính (ID) lòng phế quản sau ghép đều tăng lên ở các nhánh phế quản phân thuỳ và hạ phân thuỳ RB1, RB4, RB10, độ dày thành (WT) giảm đi ở các nhánh hạ phân thuỳ RB1-1, RB4-1, RB10-1 (tuy nhiên khác biệt không có ý nghĩa thống kê với $p<0,05)$. Kết luận: Các chỉ số khí phế thũng (LAA-950), bẫy khí (LAA-856, RVC $856-950$ ), tỷ lệ \% thành phế quản (\%WA), diện tích lòng (LA), đường kính (ID), độ dày thành (WT) phế quản đo trên cắt lớp vi tính định lượng $\mathrm{QCT}$ có tương quan với FEV1, FVC, GOLD, BODE trước và sau ghép tế bào gốc, có thể sử dụng để đánh giá mức độ, giai đoạn 